\title{
Modeling of a Jig Sampling and its Application in Disc Cutter Tools
}

\author{
S. H. Yahaya ${ }^{1}$, Haeryip Sihombing ${ }^{2}$, M. Y. Yuhazri ${ }^{3}$ and H. Hasib ${ }^{4}$ \\ ${ }_{1,2,3,4}$ Faculty of Manufacturing Engineering, University of Technical Malaysia Melaka, \\ 76100 Melaka, Malaysia
}

\begin{abstract}
The operations of preparing the deform sample and round bar mainly consist of the calculation of the bar's unit weight. The Sampling process is conducted through the two cutting flows such as in line production and disc. The problems are then occurred in the second flow (in disc) in performing the cutting process on a certain length. Modeling of the jig sampling is used to solve this problem and also fully discussed throughout this paper.
\end{abstract}

Keywords- Bar, Jig Sampling, Mass Interval, Unit Weight

\section{INTRODUCTION}

The operations of preparing the deform sample and round bar mainly contain of the calculation of unit weight in the bar. Sampling process has two flows, which are gas cutting in line production and disc cutting. The problem occurred in the second flow where in this flow, the operator needs to cut deform or round bar in certain length [1]. The operators will cut the both sides of bar, and these processes can prevent the wasted time producing, human errors and expenses [2]. This problem can be solved by introducing the sampling of a jig. In addition, the process of sampling is employed in disc cutter table to assist the workers work efficiently. The flow model is shown in Fig. 1.

The procedures are to be taken to gauge the unit weight such as to obtain the sample (bar) from cooling bed, crop both end, weight samples, measure length and calculate the unit weight. Unit weight can be calculated [3] as in (1).

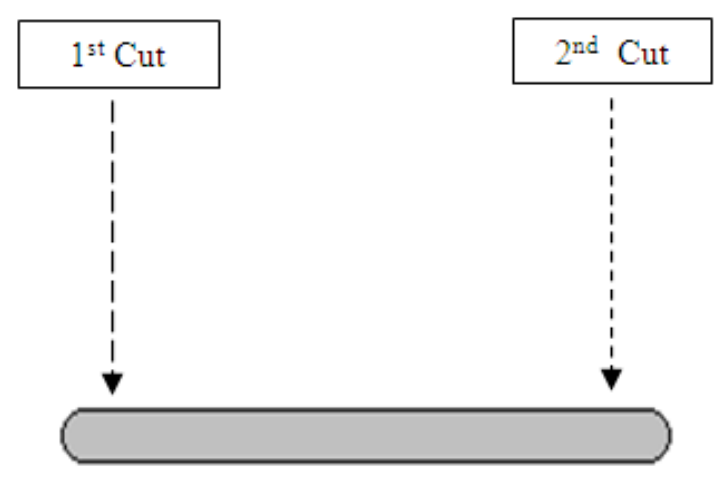

Fig.1: Cutting process and its flow model

$$
\text { unit weight }=\frac{\text { sample weight }}{\text { sample length }}
$$

\section{II.}

\section{TECHNICAL DESCRIPTIONS}

2.1 General Information on Work Holding

The following figure is about the model description that is used in the beginning of sampling process in disc cutter table. 


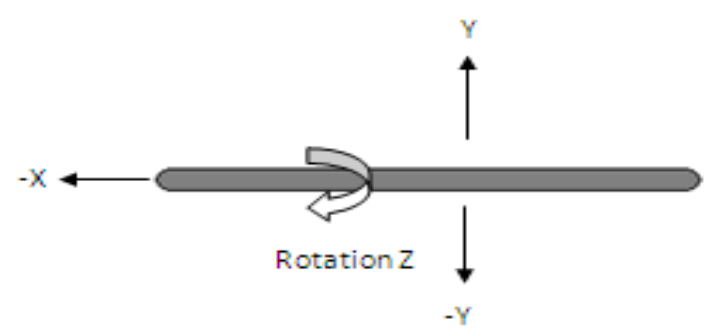

Fig. 2: Technical model applied in disc cutter table

\subsection{Function and Assembly Descriptions}

The jig is designed to control the dimension of the sample bar in accordance to -x axis [4]. With reference to the instruction booklets, bar's length should be in $600 \mathrm{~mm}$ to ensure that every facet of the sample can be cut to this size, accurately. Moreover, - $\mathrm{x}$ axis is used as a marker to the parameters such as position and dimension. The marker is performed by the counter weight and its location at the end of the vise table in automated position (Fig. 3).

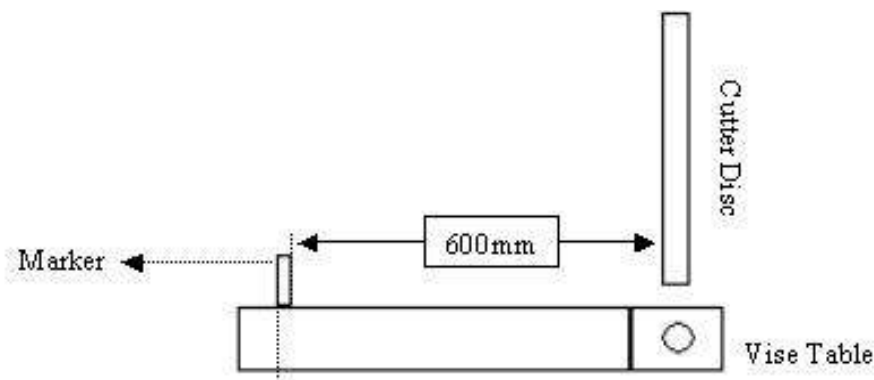

Fig. 3: Assembly model during the cutting process

\section{METHODOLOGY}

The following process flow diagram will be applied in jig sampling. The detailed process is explored in Fig. 4. In addition, the supporting equipments have been employed to accomplish this sampling such as the welding set, vise, oxy-cutting, disc cutter with drilling and milling machines. The sampling of raw materials is demonstrated in Fig. 5 while the applied designs that are used in this sampling are shown in Fig. 6.

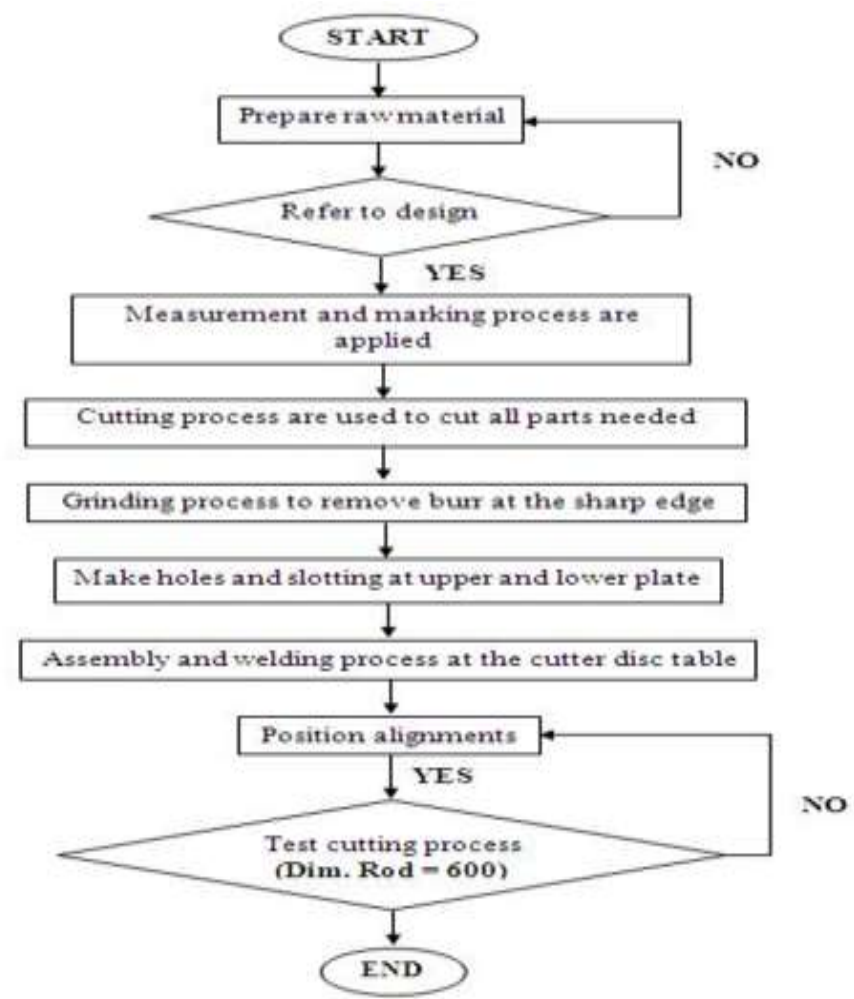

Fig. 4: Process flow diagram in the sampling jig 


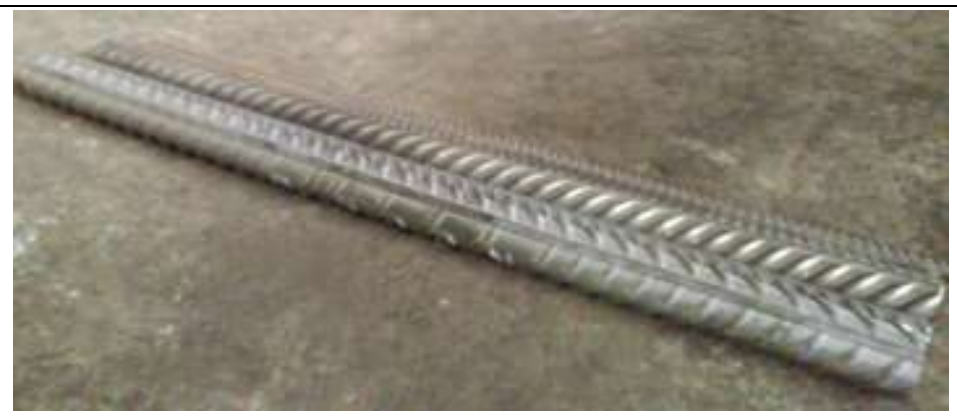

Fig. 5: Sampling of the raw materials

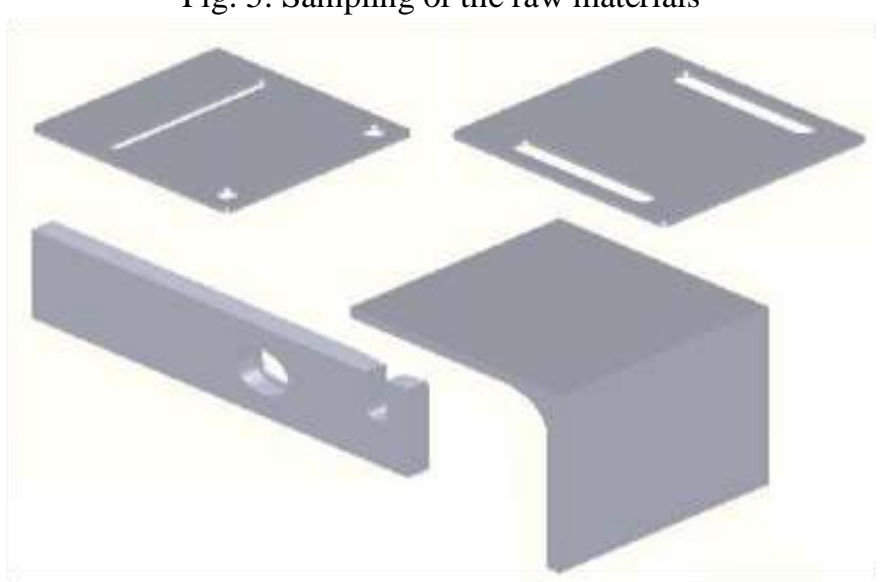

Fig. 6: The supporting designs of the sampling process are completely designed by Solidworks

IV.

\section{RESULT AND DISCUSSIONS}

The sampling began by calculating unit weight as in (1) if the parameters such as bars' length and weight are known. For example, if bar size equivalents to $20 \mathrm{~mm}$, therefore, the true value of unit weight, $S$ is equal to $0.25 \mathrm{Kgm}^{-1}$ in the reference to the existing method (normal implementation). For this case, the bars' length and weight of this size are calculated to be $0.6 \mathrm{~m}$ and $0.15 \mathrm{Kg}$.

As a result, the unit weight is $0.25 \mathrm{Kgm}^{-1}$ using (1) and the above inputs. Notice that, the calculated and true values have the same value. Then, tolerance, $\zeta$ is equal to zero. We extend this calculation to create the mass interval, $\lambda$ of unit weight to find out either the calculated unit weight is accepted (along the interval) or vice verse. This concept is continued by fitting the error to be as \pm 0.05 . The $\lambda$ is formulated as in (2). Various computations of the unit weights in accordance to the bar size using (1) and (2) are also shown in Table 1 . We can see clearly that the calculated values (in fourth column) are in the range of $\lambda$ (Table 1). The $\zeta$ have the small values after comparing with $S$. Therefore, we can conclude that the calculated values (in fourth column) are the acceptable values.

$$
\lambda=(S-0.05, S+0.05)
$$

Table 1: Unit weight's computations in the modeling of a jig sampling

\begin{tabular}{ccccccr}
\hline \hline $\begin{array}{c}\text { Bar } \\
\text { Size } \\
(\mathbf{m m})\end{array}$ & $\begin{array}{c}\text { Bar } \\
\text { Length } \\
(\mathbf{m})\end{array}$ & $\begin{array}{c}\text { Bar } \\
\text { Weight } \\
(\mathbf{K g})\end{array}$ & $\begin{array}{c}\text { Unit } \\
\text { Weight } \\
\left(\mathbf{K g m}^{-1}\right)\end{array}$ & $\begin{array}{c}\boldsymbol{S} \\
\left(\mathbf{K g m}^{-\mathbf{1}}\right)\end{array}$ & $\begin{array}{c}\boldsymbol{\lambda} \\
\left(\mathbf{K g m}^{-\mathbf{1}}\right)\end{array}$ & $\boldsymbol{\zeta}$ \\
10 & 0.6 & 0.38 & 0.63 & 0.62 & $(0.57,0.67)$ & 0.01 \\
12 & 0.6 & 0.52 & 0.87 & 0.89 & $(0.84,0.94)$ & -0.02 \\
16 & 0.6 & 0.93 & 1.55 & 1.58 & $(1.53,1.63)$ & -0.03 \\
20 & 0.6 & 0.15 & 0.25 & 0.25 & $(0.20,0.30)$ & 0.00 \\
25 & 0.6 & 0.22 & 0.37 & 0.39 & $(0.34,0.44)$ & -0.02 \\
32 & 0.6 & 0.38 & 0.63 & 0.63 & $(0.58,0.68)$ & 0.00 \\
\hline \hline
\end{tabular}

\section{CONCLUSION AND RECOMMENDATIONS}

This paper has explored the modeling of a jig sampling and its applications in disc cutter table. By using this exploration, it saves the time of producing and energy, human errors and some expenses. As shown in Table 1, it seems that the calculated values (unit weight) are highly accurate due to the comparison of the true value, $S$. Therefore, these calculations can be concluded as the acceptable values. In future, we would like to 
Modeling of a jig sampling and its application in disc cutter tools

suggest the integrations between sampling and modeling techniques to be applied in engineering fields in order to help and solve the related problems. These techniques are simple and easy to use and handle.

\section{Acknowledgements}

This research was supported by Universiti Teknikal Malaysia Melaka. The authors gratefully acknowledge to everybody for their helpful comments.

\section{REFERENCES}

[1] S. Kaldor, A. M. Rafael, and D. Messinger, On the CAD of Profiles for Cutters and Helical Flutes - Geometrical Aspects, CIRP Annals - Manufacturing Technology, 37(1), 1988, 53-56.

[2] R. Iankov, Finite element simulation of profile rolling of wire, Journal of Materials Processing Technology, 142(2), 2003, 355-361.

[3] T. El Maaddawy, and K. Soudki, A model for prediction of time from corrosion initiation to corrosion cracking, Cement and Concrete Composites, 29(3), 2007, 168-175.

[4] A. Y. C. Nee, Z. J. Tao, and A. Senthil Kumar, An Advanced Treatise on Fixture Design and Planning (Series on Manufacturing Systems and Technology) (New Jersey: World Scientific Pub Co Inc, 2004). 